\title{
Durability of the Reinforced One-Part Alkali-Activated Slag Mortars with Different Fibers
}

\author{
Z. Abdollahnejad ${ }^{1,2} \cdot$ M. Mastali $^{1} \cdot$ M. Falah ${ }^{1} \cdot$ K. Mohammad Shaad $^{1} \cdot$ T. Luukkonen $^{1} \cdot$ M. Illikainen ${ }^{1}$
}

Received: 1 July 2019 / Accepted: 3 February 2020 / Published online: 10 February 2020

(c) The Author(s) 2020

\section{Abstract}

This paper investigates the effects of reinforcing one-part alkali-activated slag binders (OAASs) with different types of fiber (steel, polyvinyl alcohol [PVA], basalt, and cellulose) and fiber combinations (single and hybrid) on the mechanical and durability properties of OAASs. All OAASs were reinforced by a $1 \%$ fiber volume fraction. Compressive and flexural strengths were the mechanical properties, which were addressed. The durability of the reinforced OAASs was examined based on water absorption by immersion and capillary, acid resistance, high temperature resistance, carbonation resistance, and freeze/thaw resistance. The experimental results showed that the fiber type and combination greatly affects the mechanical and durability properties of OAASs. Moreover, the influence of fiber type and combination on high temperature resistance and freeze/thaw resistance is greater than the influence on acid resistance and carbonation resistance.

\section{Graphic Abstract}

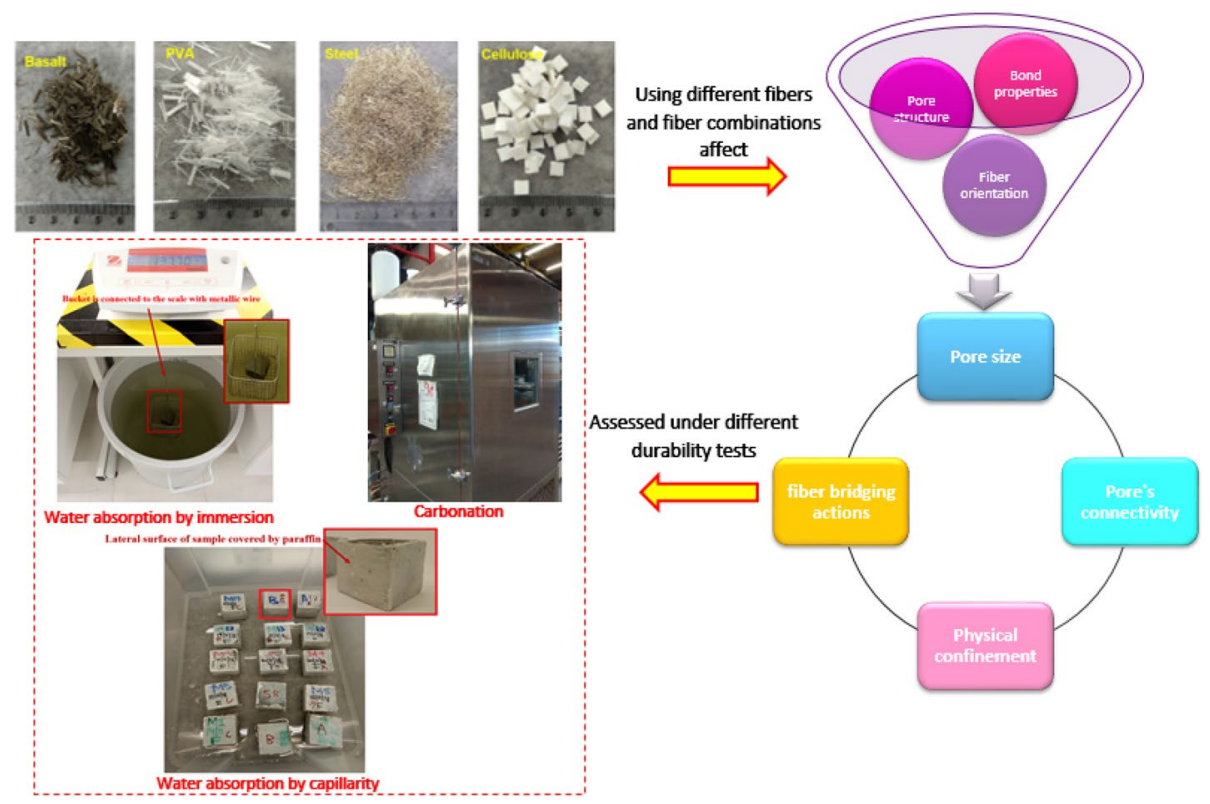

Keywords One-part alkali activated binders $\cdot$ Fiber reinforced mortars $\cdot$ Mechanical and durability properties $\cdot$ Fiber type $\cdot$ Fiber combination

Z. Abdollahnejad

zahra.abdollahnejad@uconn.edu

Extended author information available on the last page of the article 


\section{Statement of Novelty}

Few studies have reported the durability performance of fiber-reinforced one-part alkali activated slag binders, and there is no extensive experimental study has been conducted on the effects of using different fibers and fiber combinations as reinforcement on fiber-reinforced one-part alkali activated slag binders' mechanical and durability properties. Moreover, the mechanisms of durability aspects on hardened state properties

\section{Introduction}

The growth of global construction has contributed to the increase in the amount of ordinary Portland cement (OPC) concretes. However, the production of OPC-based concretes and transportation of raw materials results in significant $\mathrm{CO}_{2}$ emissions into the atmosphere. Cement contributes more $\mathrm{CO}_{2}$ emissions than other components in OPC-based concretes [1]. Therefore, alkali-activated materials with variable raw material availabilities, hydration reactions, costs, and $\mathrm{CO}_{2}$ emissions due to production have been proposed as alternatives to OPC-based concretes, showing acceptable mechanical and durability properties as well as lower environmental impacts [2]. Alkali-activated materials are commonly comprised of aluminosilicate precursors (such as fly ash, volcanic ash, or metakaolin), alkali activators (such as sodium hydroxide and sodium silicate), and aggregates [3-7]. Although the use of alkali-activated materials has some environmental advantages, liquid alkali activators are corrosive, viscous, difficult to handle, and not user-friendly [4]. Thus, some researches have made efforts to replace aqueous alkali activators with solid activators [8-10]. These alkali-activated binders are called one-part alkali-activated materials, and they have various advantages over conventional alkali-activated materials with aqueous alkali solutions, which are called two-part alkali-activated materials.

Various studies have reported the high potential of ground-granulated blast-furnace slag (GGBFS) as a main binder in alkali-activated materials. The developed alkaliactivated slag binders (AASs) contains high calcium content [11], which could lead to rapid setting time [12], low hydration heat [13], and acceptable mechanical and durability properties [13-15].

Combination of the benefits of one-part alkali-activated materials and GGBFS as the main precursor resulted in the development of one-part alkali-activated slag binders [16-19]. Similar to other cementitious compositions, the plain AASs suffer from brittleness under flexural and tensile loadings. Moreover, AASs exhibit much greater drying shrinkage than OPC-based compositions [2]. Therefore, one of the easiest ways to increase ductility and decrease drying shrinkage is to use fiber to reinforce plain compositions. A few investigations have implemented such an approach to clarify the effects of adding different fibers on the mechanical characteristics of OAASs [16]. Although various studies have been conducted on different aspects of the fresh and hardened state properties of fiber reinforced alkali activated mortars (with liquid sodium silicate), such as: rheological properties (reinforced with polyvinyl alcohol (PVA) fibers) [20], bending properties (steel and Polypropylene (PP) [21], PP [22], steel [23-25], carbon [26]), durability properties (PP [22], refractory fibers [27]), and ultra-high performance fiber reinforced mortars (PVA [28], polyethylene [29, 30], steel [31]). All of these investigations confirmed the positive influential impacts of fibers on alkali activated materials, which the effects of reinforcements majorly depend on the physical and mechanical properties of fiber, bond properties at interfacial transition zone (ITZ) between fiber/matrix, and binding properties and compactness of the matrix.

To the best of the author's knowledge, although a few studies have reported the durability performance of fiberreinforced AASs [32, 33], no extensive experimental study has been conducted on the effects of using different fibers as reinforcement on OAASs' mechanical and durability properties. It is worth stating that there are some investigations regarding development of ultra-high fiber reinforced concrete using reinforcement of one-part alkali activated materials with Polyethylene (PE) and PVA fibers [34-36]. Moreover, the impacts of using different curing regimes on the mechanical performances of the reinforced OAAS with steel and PVA fibers were investigated [16], however, no one reported the performance of these binders under harsh conditions. To enable commercial use of one-part alkaliactivated materials, it is necessary to assess the performance of fiber-reinforced OAASs under harsh conditions. This study aims to clarify the damage and the effects of each fiber type and combination on the durability performance of reinforced OAASs.

\section{Experimental Plan}

\section{Materials and Mixed Design}

The mixed compositions in this study are comprised of GGBFS (Finnsementti, Finland), solid anhydrous sodium metasilicate (Alfa Aesar, Germany), sand (Normensand, Germany), superplasticizer (BSF), and water. The binder consists of GGBFS and sodium metasilicate (molar ratio of $\mathrm{SiO}_{2} / \mathrm{Na}_{2} \mathrm{O} \approx 0.9$, water content $2.5 \%$ ). The ingredients of the mixed design were based on [17]. The content of the GGBFS was $90 \%$ of the total mass, and the other $10 \%$ was assigned to sodium metasilicate. Also, GGBFS had a $d_{50}$ 
of $10.8 \mu \mathrm{m}$ and a density of $2.93 \mathrm{~g} / \mathrm{cm}^{3}$, and its chemical composition is as follows: $\mathrm{MgO} \approx 10 \%, \mathrm{Al}_{2} \mathrm{O}_{3} \approx 9 \%, \mathrm{SiO}_{2}$ $\approx 33 \%, \mathrm{Na}_{2} \mathrm{O} \approx 0.5 \%, \mathrm{SO}_{3} \approx 4 \%, \mathrm{Fe}_{2} \mathrm{O}_{3} \approx 1 \%, \mathrm{TiO}_{2} \approx 2 \%$, and $\mathrm{CaO} \approx 39 \%$. Sodium metasilicate was also prepared by mixing $\mathrm{SiO}_{2}$ with $\mathrm{Na}_{2} \mathrm{O}$ in 1:1 molar ratio. The size distribution of standard sand has been illustrated in Fig. 1a according to EN 196-1. Standard sand (minimum and maximum particle sizes of 0.08 and $2 \mathrm{~mm}$, respectively) was used in accordance with the standard EN 196-1 [37]. The ratio of sand to binder (GGBFS and sodium metasilicate) was 2. To reduce the amount of water, a polycarboxylate-based superplasticizer (SP supplied from BSF company) with a mass of 0.014 of the total binder mass was mixed by the available water and then added to the composition. Yang et al. [38] noticed that polycarboxylate-based superplasticizer showed retarding effect on alkali-activated fly ash/slag pastes with negligible effects on the heat of hydration. Using modified admixtures introduces high negative charge, so that the particles are repelled and deflocculated, and subsequently water released. The modified polycarboxylate admixture in addition to electrostatic repulsion benefits from steric repulsion produced by lateral ether chains on the molecule [39]. A constant water to binder ratio of 0.45 was used in all mixtures. In [17], a constant water to binder ratio of 0.35 was used for the plain alkali activated mortars. Since in this paper, different fibers were used to reinforce the mixtures, the content of water was increased to provide good flowability and have fully dispersed fibers in fresh mortars.

Different fiber types (PVA, short length steel, cellulose, basalt) and combinations were used to reinforce a plain OAAS. Figure $1 \mathrm{~b}$ shows the fibers that were used, and Table 1 lists the physical and mechanical properties of these fibers. In this study, the total volume of the fiber was constant (1\%). When a combination of fibers was used, each type comprised $0.5 \%$ of the total volume. In order to reduce the cost of final construction materials, OAAS should be reinforced with the minimum amount of fiber. The preliminary studies revealed that using fiber volume fraction above $1 \%$ leads to improve flexural strength, therefore, this fiber volume fraction was used in this study as the minimum amount of fiber. As listed in Table 2, eleven different compositions were designed and prepared for assessment with various mechanical and durability tests.

During the batching process, GGBFS, sodium metasilicate, and sand were mixed for $3 \mathrm{~min}$ in a mixer. Then, water and SP were stirred and added to the mixture, and the mixing
Fig. 1 a Grain size distribution according to EN 196-1 b The fibers used to reinforce a plain OAAS

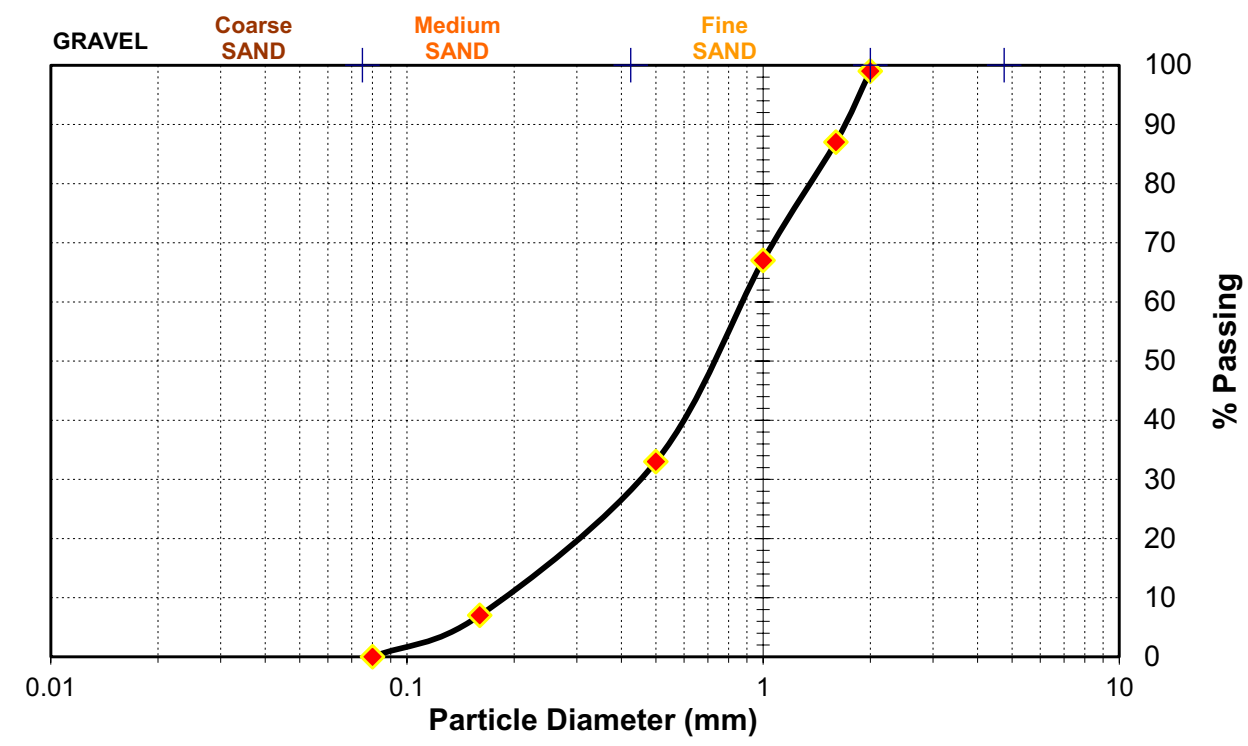

(a)
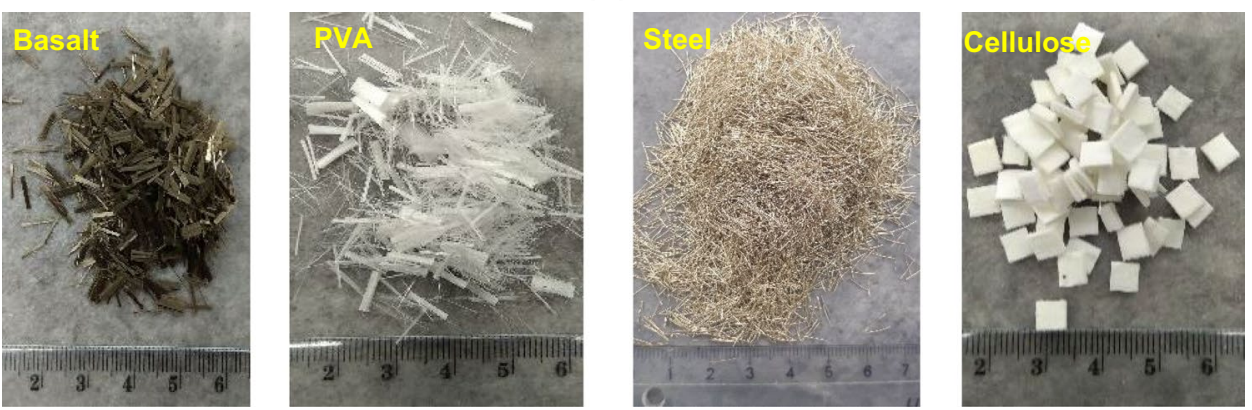

(b) 
Table 1 Physical and mechanical properties of the employed fibers

\begin{tabular}{llcccc}
\hline Fiber type & $\begin{array}{l}\text { Length/diameter } \\
(\mathrm{mm} / \mathrm{mm})\end{array}$ & $\begin{array}{l}\text { Elastic modu- } \\
\text { lus }(\mathrm{GPa})\end{array}$ & $\begin{array}{l}\text { Tensile strength } \\
(\mathrm{MPa})\end{array}$ & Density $\left(\mathrm{g} / \mathrm{cm}^{3}\right)$ & $\begin{array}{l}\text { Melting } \\
\text { temperature } \\
\left({ }^{\circ} \mathrm{C}\right)\end{array}$ \\
\hline Steel & 47 & 200.0 & 1300 & 7.80 & 1538 \\
PVA & 200 & 41.0 & 1600 & 1.30 & 220 \\
Cellulose & 117 & 8.5 & 750 & 1.10 & 150 \\
Basalt & 333 & 100.0 & 4500 & 2.63 & 1350 \\
\hline
\end{tabular}

Table 2 Mixtures, dosages, and types of fibers

\begin{tabular}{lllll}
\hline & \multicolumn{4}{l}{ Dosage and type of fiber (in Vol\%) } \\
\cline { 2 - 5 } & Steel & PVA & Cellulose & Basalt \\
\hline Reference & 0.0 & 0.0 & 0.0 & 0.0 \\
St1.0 & 1.0 & 0.0 & 0.0 & 0.0 \\
PVA1.0 & 0.0 & 1.0 & 0.0 & 0.0 \\
Cel1.0 & 0.0 & 0.0 & 1.0 & 0.0 \\
Bs1.0 & 0.0 & 0.0 & 0.0 & 1.0 \\
St0.5PVA0.5 & 0.5 & 0.5 & 0.0 & 0.0 \\
PVA0.5Ce10.5 & 0.0 & 0.5 & 0.5 & 0.0 \\
St0.5Cel0.5 & 0.5 & 0.0 & 0.5 & 0.0 \\
Bs0.5Ce10.5 & 0.0 & 0.0 & 0.5 & 0.5 \\
Bs0.5St0.5 & 0.5 & 0.0 & 0.0 & 0.5 \\
Bs0.5PVA0.5 & 0.0 & 0.5 & 0.0 & 0.5 \\
\hline
\end{tabular}

procedure continued for an additional 3 min. Finally, the fibers were gradually added to the compositions and mixed for a further $2 \mathrm{~min}$. The mix was then cast into prismatic beams $\left(40 \times 40 \times 160 \mathrm{~mm}^{3}\right)$ and cubic molds with edges of $50 \mathrm{~mm}$ and $100 \mathrm{~mm}$, and the castings were vibrated using a jolting table $(2 \times 60$ shocks, 1 shock/s). After casting, the specimens were cured in a chamber with a controlled temperature of $22{ }^{\circ} \mathrm{C}$ and relative humidity of $95 \%$ for $24 \mathrm{~h}$, then the specimens were demolded and kept in lab conditions (temperature of $23{ }^{\circ} \mathrm{C}$ and relative humidity of $35 \%$ ) until the testing day.

\section{Experimental Test Procedure}

\section{Ultrasonic Pulse Velocity}

The non-destructive ultrasonic pulse velocity (UPV) evaluation is intended to determine the quality of an OAAS by propagating the ultrasonic waves that pass through the OAAS and measuring the velocity of the pulse. Lower velocities indicate lower-quality OAASs with a higher volume of air voids, while higher velocities indicate higher-quality OAASs with greater compactness. Since the addition of fibers affects the amount of air voids in an OAAS, UPV can also be used to reflect the quality of fiber-reinforced OAAS. Equation (1) can be used to compute the pulse velocity of specimens:
$V=\frac{L}{T}$

where $\mathrm{V}$ is pulse velocity $(\mathrm{km} / \mathrm{s}), \mathrm{L}$ is the distance between two transducers $(\mathrm{mm})$, and $\mathrm{T}$ is transmission time ( $\mu \mathrm{sec})$. To assess UPV for each mixture, three prismatic beams with dimension of $40 \times 40 \times 160 \mathrm{~mm}^{3}$ were used. Later, these beams were used to obtain the flexural strength. UPV measurements were carried out on different parallel external sides of the beams and the differences in the measured UPV were ignorable.

\section{Compressive Test}

The compressive strength of cubic specimens $(50 \times 50 \times 50$ $\mathrm{mm}^{3}$ ) was obtained according to ASTM C109/C109M recommendations [40]. Compressive strength was defined by averaging three cubes after 28 days of aging. This assessment was carried out by imposing the compressive load with a displacement rate of $1.8 \mathrm{~mm} / \mathrm{min}$ under a displacement control. A hydraulic machine (Toni Technik) with a load cell of $3000 \mathrm{kN}$ was used to submit the compressive load. Equation (2) was used to determine the compressive strength:

$\sigma_{c}=\frac{F}{A}$,

where $\sigma_{c}$ is the compressive strength (MPa), $\mathrm{F}$ is the maximum compressive force $(\mathrm{N})$, and $\mathrm{A}$ is surface area of the specimen $\left(\mathrm{mm}^{2}\right)$.

\section{Flexural Test}

The flexural strength of prismatic beams $(40 \times 40 \times 160$ $\mathrm{mm}^{3}$ ) was obtained through a three-point bending (TPB) test based on the ASTM C78 recommendation [41]. Flexural strength was determined by replicating three specimens aged 28 days under a displacement control with a speed rate of $0.6 \mathrm{~mm} / \mathrm{min}$. It was calculated with Eq. (3):

$\sigma_{f}=\frac{3 F L}{2 b h^{2}}$, 
where $\sigma_{f}$ is the flexural strength, $\mathrm{F}$ is the maximum flexural load $(\mathrm{N}), \mathrm{L}$ is the span length $(120 \mathrm{~mm})$, and $\mathrm{b}$ and $\mathrm{h}$ are the width $(40 \mathrm{~mm})$ and height $(40 \mathrm{~mm})$ of beams, respectively.

\section{Water Absorption by Immersion and Capillarity}

After 28 days, water absorption by immersion and capillarity was performed using cubes with dimensions of $50 \times 50 \times 50$ $\mathrm{mm}^{3}$ and $100 \times 100 \times 100 \mathrm{~mm}^{3}$, respectively.

For water absorption by immersion, the cubes were initially placed in an oven with a temperature of $105^{\circ} \mathrm{C}$ for $24 \mathrm{~h} \mathrm{[42].} \mathrm{The} \mathrm{dried} \mathrm{specimens} \mathrm{were} \mathrm{allowed} \mathrm{to} \mathrm{cool} \mathrm{down} \mathrm{at}$ room temperature and then were weighted $\left(W_{d r y}\right)$. The dried specimens were placed underwater in a container for $48 \mathrm{~h}$. After $48 \mathrm{~h}$, the saturated weight $\left(W_{\text {sat }}\right)$ of the specimens was measured. Water absorption by immersion was determined using the following equation:

Water absorption by immersion $=\frac{W_{s a t}-W_{d r y}}{W_{d r y}} \times 100$

The subtracted suspension weight $\left(\mathrm{W}_{\text {sus }}\right)$ of cubes was determined. Using all the gathered data, the apparent porosity (i.e., open or connected) of compositions was computed as follows:

Apparent porosity $=\frac{W_{s a t}-W_{d r y}}{W_{S a t}-W_{S u s}} \times 100$

Water absorption by capillarity was conducted based on EN 1015-18:2002 [43]. Three cubes with dimensions of $100 \times 100 \times 100 \mathrm{~mm}^{3}$ were cast and prepared. A silicon layer covered the lateral surfaces of cubic specimens because this helps to avoid water evaporation and humidity transportation over such surfaces. Then, the bottom surface was placed touching water and the mass of the water absorbed through capillary rise was measured over $96 \mathrm{~h}$. Equation (6) was used to find the coefficient of capillary water absorption:

$\mathrm{A}_{\mathrm{w}}=\frac{\Delta \mathrm{B}}{\mathrm{A} \sqrt{\mathrm{t}}}$

where $A_{w}$ represents the water absorption coefficient $(\mathrm{kg} /$ $\left.\mathrm{m}^{2} / \mathrm{H}^{0.5}\right), \Delta \mathrm{B}$ represents the mass of absorbed water, and $\mathrm{A}$ represents the surface area $\left(\mathrm{m}^{2}\right)$. The gradient of the straight line identified by plotting the cumulative mass of absorbed water was used to evaluate the mass of water entering the cubic specimen per unit of area and time [43].

\section{Acid Test}

Acid resistance was measured with cubes $\left(50 \times 50 \times 50 \mathrm{~mm}^{3}\right)$ that had been cured for 28 days. The cubes were weighted before immersion in a liquid comprised of water and $3 \%$ mass of sulfuric acid (at $\mathrm{pH} 1.0)$. Then, the specimens were removed from the liquid and their weight and weight loss were computed. Three cubes were measured for each composition. The specimens immersed in the acidic environment for 9 days. Reinforcement of the cementitious (or cementless) compositions commonly increases porosity and permeability compared to the plain compositions, therefore, it can be assumed that fiber reinforced compositions are more susceptible to mass and strength losses exposed to the acidic environments. On the other hand, the lowest $\mathrm{pH}$ sulfuric acid ( $\mathrm{pH} 1)$ was selected to assess the highest impacts of the chemical attacks on AAS [44]. Therefore, exposure time to acidic environment was reduced to 9 days.

\section{High Temperature Test}

Resistance against high temperatures was evaluated by exposing three cubes $\left(50 \times 50 \times 50 \mathrm{~mm}^{3}\right)$ from each mixture to a temperature of $600{ }^{\circ} \mathrm{C}$ for $3 \mathrm{~h}$. After exposure to a high temperature, they were cooled to room temperature and then their compressive strength was measured. The temperature from the range of 400 to $800{ }^{\circ} \mathrm{C}$ could be critical to the strength loss in concrete [45], therefore, the temperature of $600{ }^{\circ} \mathrm{C}$ was selected for being elevated.

\section{Freeze/Thaw Test}

Three prismatic beams from each mixture were assessed under cyclic freeze/thaw conditions. The specimens were kept in a tray and filled to $20 \mathrm{~mm}$ with distilled water. In accordance with the PD CEN/TS 12390-9:2016 standard, temperature varied from -20 to $+15{ }^{\circ} \mathrm{C}$ [46]. The duration of each cycle was $8 \mathrm{~h}$. The specimens were subjected to $-20^{\circ} \mathrm{C}$ for $2 \mathrm{~h}$, to temperature variations for $4 \mathrm{~h}$, and then to $15^{\circ} \mathrm{C}$ for $2 \mathrm{~h}$. All specimens experienced 60 freeze/ thaw cycles.

\section{Carbonation Test}

The carbonation test was performed with three prismatic beams $\left(40 \times 40 \times 160 \mathrm{~mm}^{3}\right)$ from each mixture, which were exposed to $23^{\circ} \mathrm{C}, 60 \%$ relative humidity, and $5 \% \mathrm{CO}_{2}$ gas for 7 days [32]. Then, the impacts of carbonation were evaluated on flexural and compressive strength.

\section{Results and Discussion}

\section{UPV}

The impacts of using each fiber type and combination on the UPV are shown in Fig. 2. Reinforcement of OAASs with different fiber types and combinations had no significant impact 


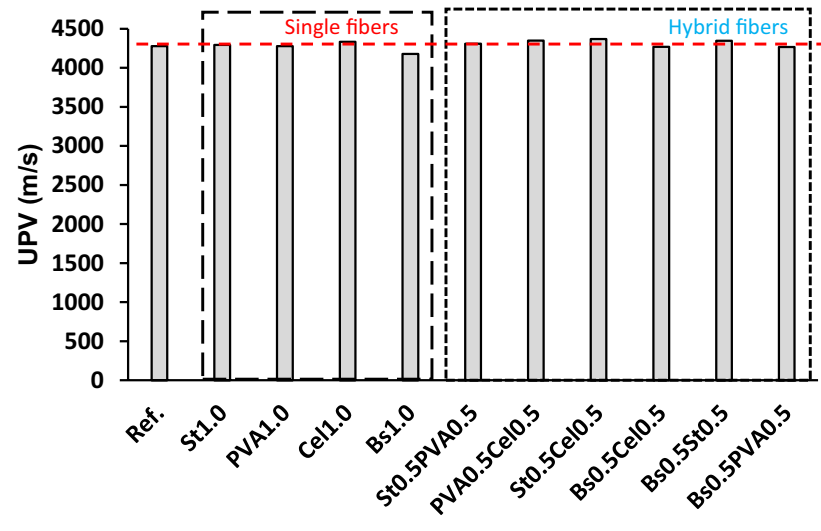

Fig. 2 Effects of using different fibers on the UPV

on the UPV. Increases or decreases in the UPV varied within $2 \%$ of the UPV of the plain reference mixture. The greatest increases and decreases in the UPV in relation to the reference mixture were observed in the OAASs reinforced by St0.5Cel0.5 (+2\%) and Bs1 (-2\%), respectively. In general, it could be concluded that adding a particular fiber did not have a great impact on the UPV or air voids, although this test does not assess air voids' connectivity, size, and tortuosity.

\section{Mechanical Strengths}

Reinforcement of a plain OAAS could either increase or decrease the compressive strength, which depends on the pore structure and capacity of fibers to arrest further opening of cracks [47-49]. Increasing porosity by adding fibers decreases the compressive strength of an OAAS, while arresting further opening of cracks increases it. In general, addition of fibers increases the flexural strength caused by fiber bridging action [47-50], although some degradation in flexural strength was reported and attributed to various reasons, such as use of a high amount of fibers (which resulted in a balling effect), the synergic impacts of hybrid fibers, the properties of bonds at the ITZ between a fiber and matrix, and the impact of these properties on the fiber failure mode [47-49].

The mechanical properties of fiber-reinforced OAASs were addressed in terms of compressive and flexural strength. These properties are shown in Fig. 3. The results reported in Fig. 3a indicate that compressive strength is significantly affected by reinforcement of a plain OAAS with different fiber types and combinations. The addition of single steel and PVA fibers increased the compressive strength by around $25 \%$ and $20 \%$, respectively, while the addition of cellulose and basalt fibers reduced the compressive strength by about $20 \%$ and $50 \%$, respectively. It seems that using short length steel fibers and PVA could

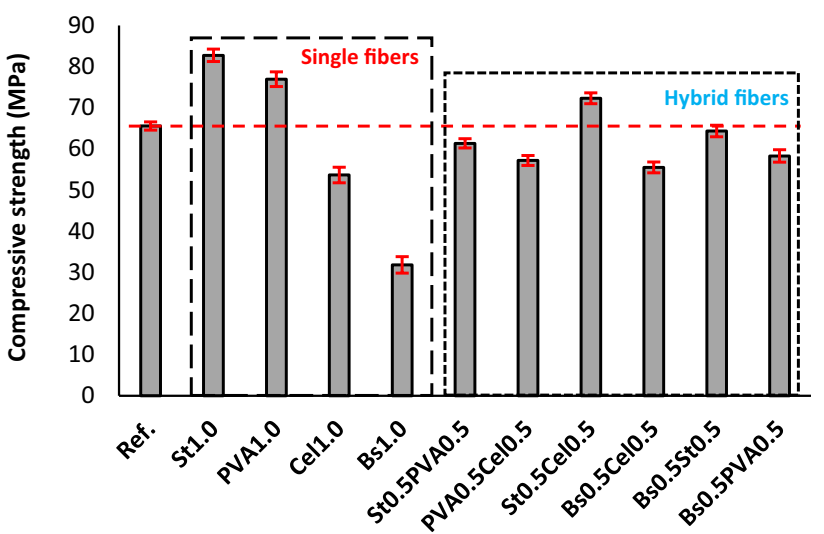

(a)

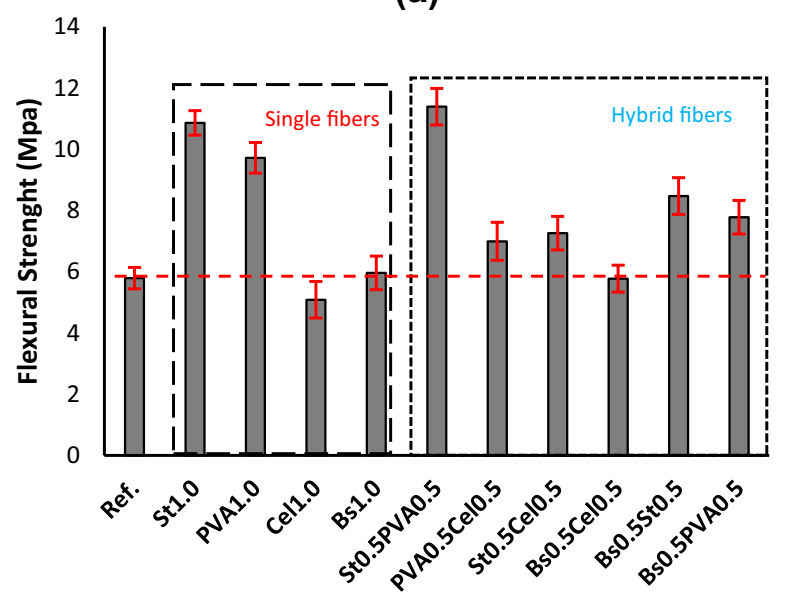

(b)

Fig. 3 Effects of using different fibers on a compressive strength and b flexural strength

arrest further opening of cracks by bridging these cracks. Interestingly, a hybrid combination of steel and PVA fibers both decreased compressive strength compared to the reference mixture due to the synergic impacts of fibers. Except ST0.5Cel0.5 ( $\approx 10 \%$ increase), all hybrid fiber combinations decreased compressive strength. The compressive strength loss should be investigated by the pore structure of the reinforced compositions. In this regard, the results reported in the sections UPV and water absorption by immersion and capillarity were used to assess indirectly the pore structures of the compositions. The reported values of the UPV reflect this fact that total porosity is not affected by fiber reinforcement, however, it will be shown (in "Water Absorption by Immersion and Capillary" section, water absorption by capillarity) that pores' connectivity is governed by the fiber combinations. High and low pore's connectivity and tortuosity with equal total porosity means that the diameters of pores are fine and coarse, respectively. According to the compressive strength, strength gain and loss were mainly 
observed in the reinforced compositions with fine and large pore's diameter, respectively.

Comparison of the mechanical strength of different OAASs revealed that the impacts of hybrid fibers on flexural strength are greater than the impacts on compressive strength. As indicated in Fig. 3b, except for Cel1 and Bs0.5Cel0.5, the addition of single or hybrid fibers increased flexural strength compared to plain OAASs due to bridging function of fibers. The maximum increase in flexural strength $(\approx 2$ times the baseline) was achieved with $\mathrm{St} 1$ and $\mathrm{St} 0.5 \mathrm{Cel} 0.5$, although the compressive strength of the mixture reinforced with hybrid steel and PVA fibers was decreased.

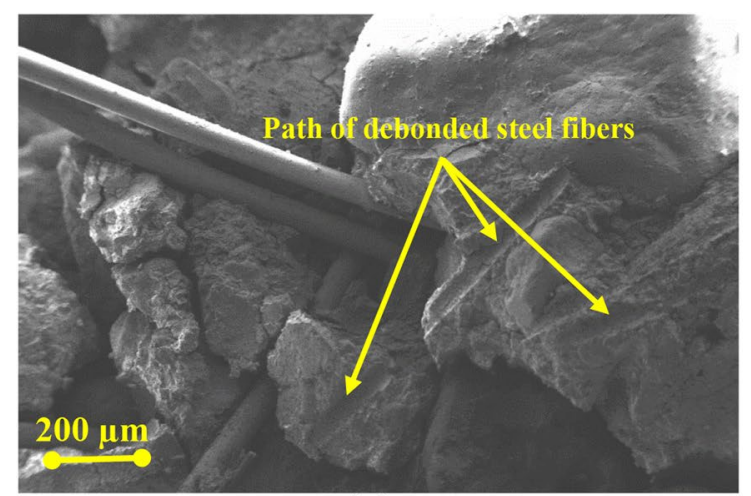

(a)

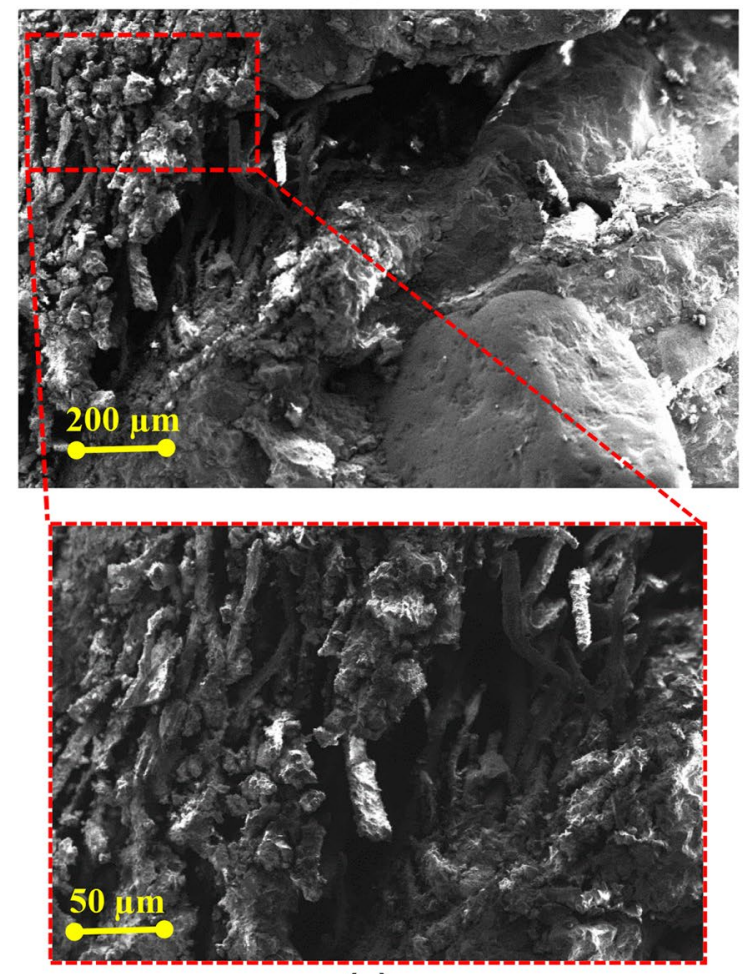

(c)
Moreover, it was found that using basalt and cellulose as single (Bs1 and Cel1) and hybrid (Bs0.5Cel0.5) fibers did not improve mechanical strength. As shown in "Water Absorption by Immersion and Capillary" section, using these fibers significantly increases the total porosity of the mixtures and a hard bond did not form at the ITZ of fiber/matrix and thus further opening of the crack was not arrested. Combination of Bs1 and Cel1 with steel and PVA fibers as hybrid increased mechanical strength as this enhanced the bonding properties of the fibers at the fiber/ matrix ITZ. However, addition of steel fibers had a greater impact than addition of PVA fibers.

Figure 4 indicates the failure modes of fibers using scanning electron microscope (SEM) images, which provided

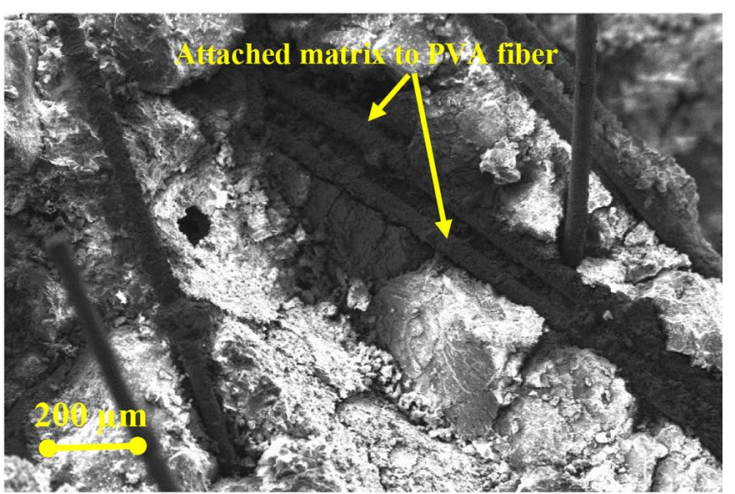

(b)

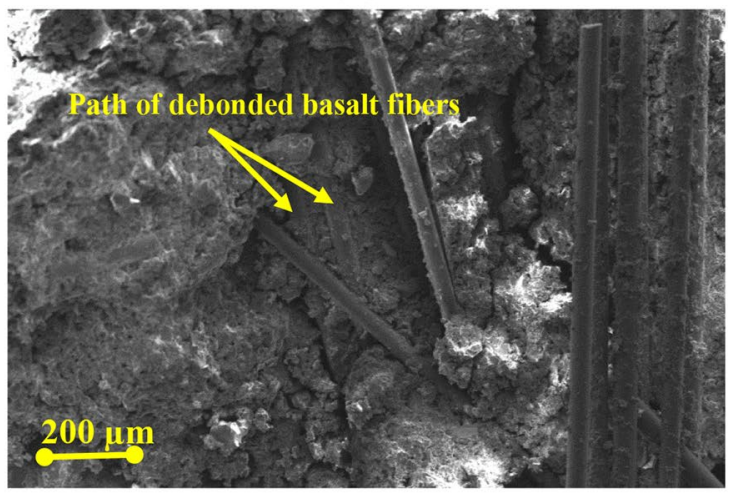

(d)

Fig. 4 SEM images from fracture surface of the reinforced OAAS with: a steel fiber; $\mathbf{b}$ PVA fiber; $\mathbf{c}$ cellulose fiber; $\mathbf{d}$ basalt fiber 
from the fracture surface of specimens. Accordingly, it seems steel and basalt fibers were dominantly debonded from their surrounded matrix and paths of debonding in the matrix can be clearly observed. In contrast, PVA fibers were mainly ruptured due to form hard bond between fibers and it surrounded matrix. SEM images show that matrix has been attached to the multi-layers of cellulose fibers.

\section{Water Absorption by Immersion and Capillary}

Reinforcement of an OAAS could either provide physical confinement or increase the permeability of the composition. Domination of physically confinement of the composition enhances the durability performance, while increasing the permeability decreases it. Therefore, enhancement or degradation of durability properties depend significantly on the physical and mechanical properties of the fiber are used.

The effect of reinforcing a plain OAAS with different fibers on pore connectivity and tortuosity have been indirectly investigated by water absorption by immersion and capillary tests. Figure 5 depicts the results of a water absorption test of each composition. As expected, the addition of fibers, except St 1, increased the compositions' porosity and water absorption by immersion (see Fig. 5a). The maximum water absorption by immersion was around $10 \%$ in OAASs reinforced with cellulose and basalt as single and hybrid fibers, which is more than $65 \%$ than the reference mixture. It is worth stating that water immersion by capillary action is governed by the capillary network and pore tortuosity. As indicated in Fig. 5b, use of steel and PVA fibers resulted in more connected pores, and therefore a higher cumulative mass of water, compared to use of cellulose and basalt fibers. This means that using steel and PVA fibers produces more connected pores and tortuosity, while cellulose and basalt fibers generate larger pores as less connected pores and tortuosity. Differences in the pore structure of OAASs are determined by differences in the physical and mechanical properties of the fibers, which affect the fibers' distribution and dispersion. Figure $5 \mathrm{c}$ displays the capillary water absorption coefficients, which varied from 0.14 (for Cel1) to 0.165 (for $\mathrm{St} 1$ ) $\mathrm{kg} / \mathrm{m}^{2} \cdot \mathrm{min}^{0.5}$. These values are much lower than the $0.18-0.51 \mathrm{~kg} / \mathrm{m}^{2} \min ^{0.5}$ reported in $[51,52]$ for plain fly ash-based alkaline mortars. The maximum and minimum increases in the capillarity network were observed in OAAS reinforced with steel $(\approx 10 \%)$ and cellulose $(7 \%)$ fibers, respectively. Figure 5d illustrates the apparent porosity of

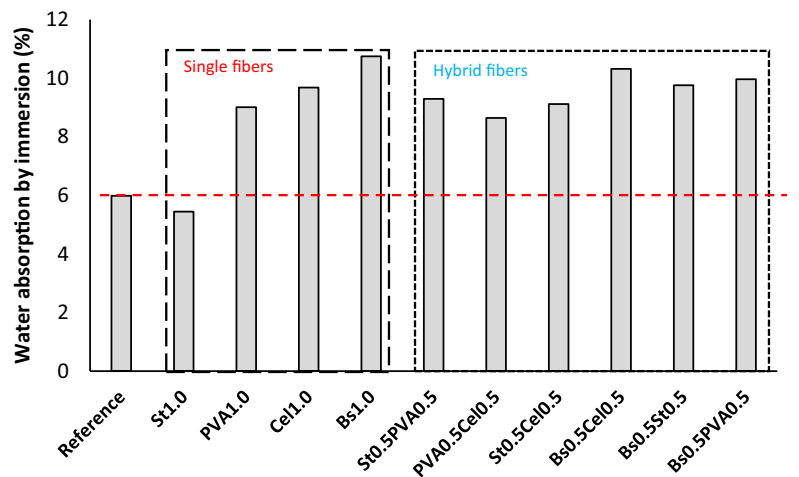

(a)

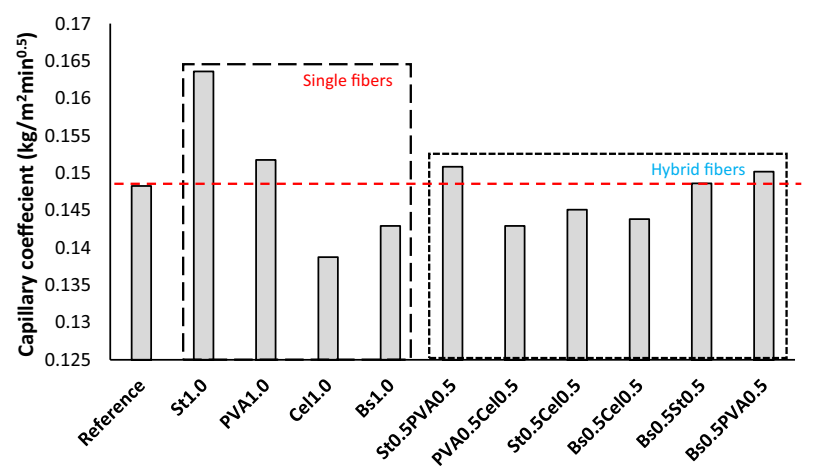

(c)

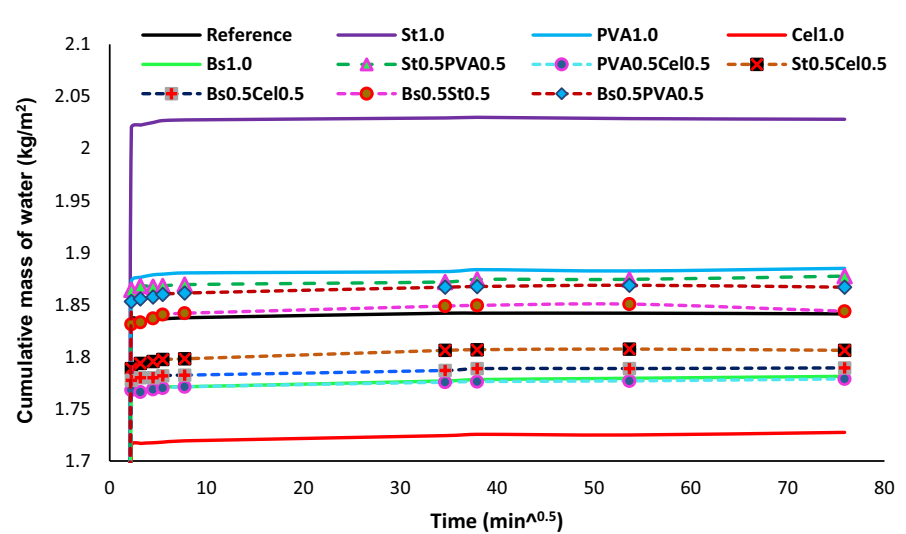

(b)

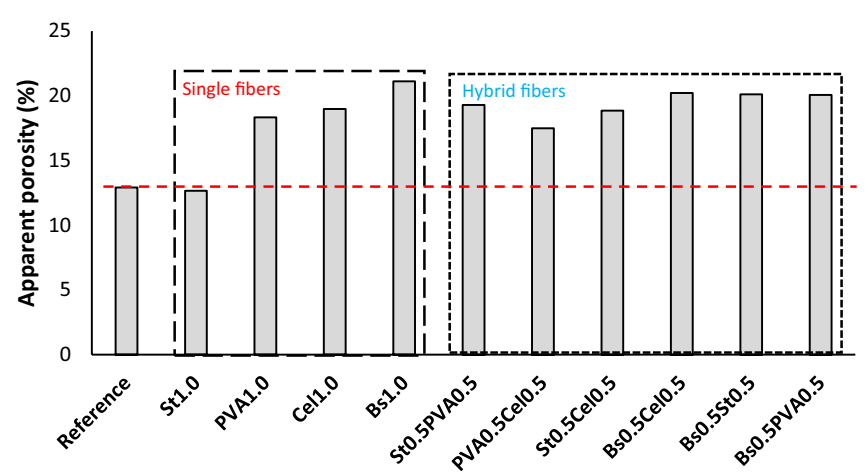

(d)

Fig. 5 Effects of reinforcing OAAS with fiber on a water absorption by immersion, $\mathbf{b}$ the cumulative mass of water, $\mathbf{c}$ the capillary coefficient, and $\mathbf{d}$ apparent porosity 
different mixtures. The results were in line with those for water absorption by immersion. In the OAASs reinforced with single fibers, the maximum porosity was $21 \%$ (for Bs 1 ), which is $65 \%$ higher than the reference mixture. The addition of all types of fibers as a combination increased the apparent porosity by $35-55 \%$ compared to the reference mixture.

\section{Acid Resistance}

In the plain AAS, acid resistance could be governed by different parameters such as permeability and porosity of AAS, and $\mathrm{Ca} / \mathrm{Si}$ and $\mathrm{Al} / \mathrm{Si}$ ratios [53-56]. Using GGBFS in the matrix leads to having a fine pore structure and compact matrix, which decreases the penetration of acid into the binder, and results in a lower loss of aluminum leached from gel structures [53]. However, the porosity notably increases with a low amount of penetrated acid to the compact matrix when exposed to the sulfuric acid in the plain AASs, which high amount of calcium in GGBFS makes it more prone to porosity increase under acid attack.

Reinforcement of OAAS affects acid resistance due to the resultant increase in physical confinement and permeability (and total porosity), which are affected by fibers' type, length, shape, and mechanical properties.

Figure 6 shows the resistance of OAAS reinforced with different fibers and exposed to 3\% sulfuric acid as normalized mass changes and mass changes. All the plain and reinforced OAASs had high acid resistance, and both the plain and reinforced OAASs had low mass loss $(\leq 2 \%$ of the initial mass). After exposure to an acidic environment for 9 days, the maximum and minimum mass losses were recorded for PVA0.5Cel0.5 $(\approx 2 \%)$ and Bs0.5St0.5 $(\approx 0.4 \%)$, respectively. In the OAASs reinforced with single fibers, steel and basalt fibers were best performance in minimizing mass loss after exposure to an acidic environment $(\approx 1 \%)$. Cel1 was associated with the maximum mass loss over time (1\% after 3 days and $1.7 \%$ after 9 days) among the mixtures reinforced with single fibers, but all such mixtures had lower mass loss than the reference mixture. The efficiency of hybrid fibers in terms of mass loss depends on the combination of fibers. Funke et al. assessed the impacts of using different short fibers (glass, carbon, basalt) in alkali-activated fly ash binders exposed to an alkali attack $(1 \mathrm{~mol} / \mathrm{L} \mathrm{NaOH})$ [57]. Mass loss varied from $0.7 \%$ (carbon fiber) to $5 \%$ (basalt fiber) for these binders after 9 days. They found that the efficiency of fibers depends on the alkali resistance of fibers against acidic environments.

Also, it should be mentioned that the results reported here in this paper is for a limited time of acid resistance and this test could be prolonged for several months, therefore, this assessment under longer test periods may be suggested to be conducted in future investigations.

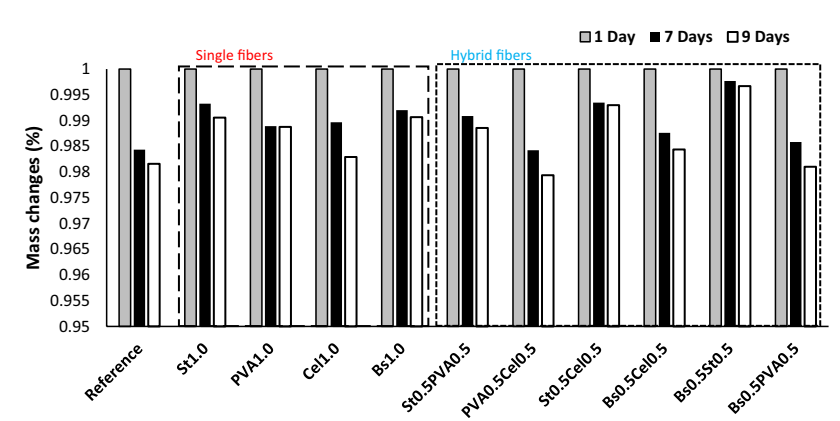

(a)

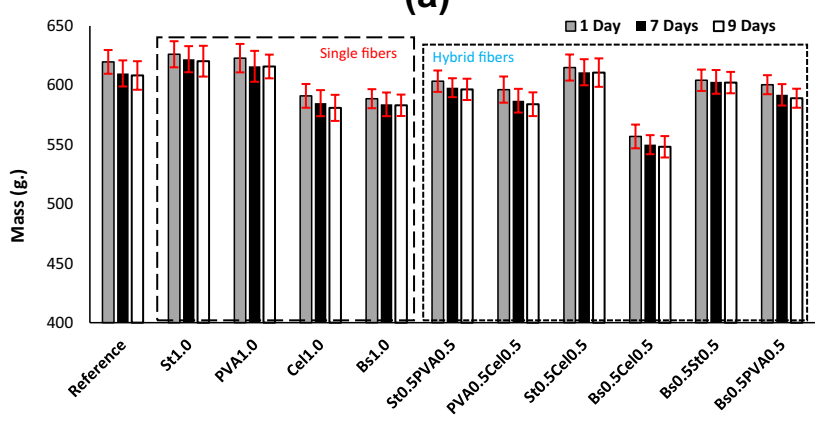

(b)

Fig. 6 a Normalized mass changes of the mixtures exposed to acid test; b Mass changes of the mix-tures exposed to acid test

\section{High Temperature Resistance}

Exposing fibers to high temperatures caused fibers to melt and created micro-channels and extra air voids in the mixtures [58]. In addition, temperature affects the physical and mechanical properties of fibers, their bonding properties at the fiber/matrix ITZ, and matrix properties. In some cases, fibers do not reach a melting point under high temperatures, but the weak bond properties at the fiber/matrix ITZ and/ or weak matrix properties could affect the performance of fiber-reinforced OAASs. Moreover, it should be mentioned that the use of temperature of $600{ }^{\circ} \mathrm{C}$ certainly damages the matrix properties and strength loss is mainly caused by bonding properties at the fiber/matrix ITZ and matrix properties. Therefore, strength loss depends on the temperature to which specimens are exposed, the fibers that are used, and the properties of the matrix.

Steel fibers can resist strength loss against high temperatures in both single and hybrid systems (see Fig. 7). The residual strength in St1 was around $40 \%$ of the un-heated strength. The residual strength of St 1 reached about $33 \mathrm{MPa}$ after heating for $3 \mathrm{~h}$ at $600{ }^{\circ} \mathrm{C}$, which is an acceptable strength for fire resistance in real structural applications. Nonmetallic single fibers led to strength loss of $85-90 \%$ compared to un-heated strength.

Following the high temperature exposure, no evidence of the nonmetallic fibres was observed. The maximum strength 


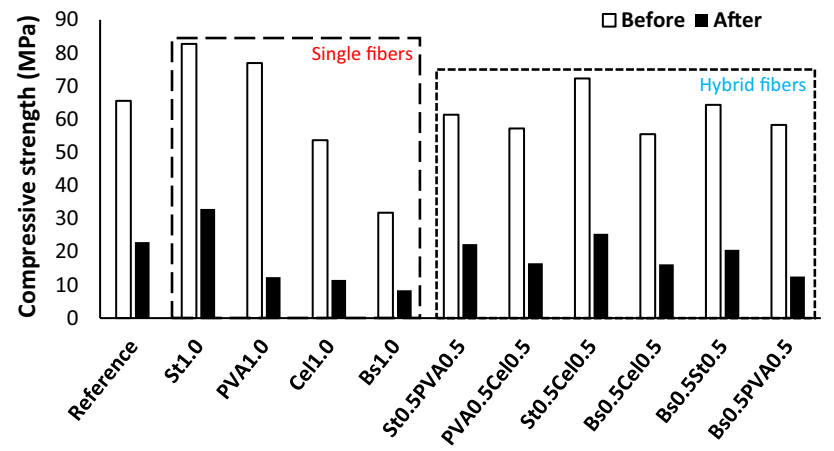

Fig. 7 Effects of exposure to a high temperature on OAASs reinforced with different fibers

loss (around 90\%) was reported for Bs1. The un-heated strength of the OAAS reinforced with PVA fibers was higher than that of the reference mixture $(\approx 20 \%)$, but exposure to a high temperature melted the PVA fibers (temperature of melting point for PVA fibers is $\approx 220^{\circ} \mathrm{C}$ ) and led to the creation of extra micro-channels, increasing porosity.

This caused the residual strength $(\approx 12 \mathrm{MPa})$ to become even lower than that of the heated reference mixture $(\approx$ $23 \mathrm{MPa}$ ). Inclusion of steel fibers in hybrid-reinforced OAAS reduced strength loss, limiting it to $70-75 \%$, while inclusion of nonmetallic fibers led to strength loss of 80-85\%.

Puertas et al. used glass fiber to reinforce AASs under consistently elevated temperatures up to $1200^{\circ} \mathrm{C}$ [33]. After reaching $600{ }^{\circ} \mathrm{C}$, both plain and reinforced AASs indicated $60 \%$ strength loss. Mastali et al. reinforced AASs with different fibers (PVA, polypropylene, cellulose, steel, and basalt) and assessed their resistance to a high temperature $\left(600^{\circ} \mathrm{C}\right)$ for $4 \mathrm{~h}$ [32]. Similar to the findings of the present study, the minimum compressive and flexural strength loss (around $75 \%$ and $70 \%$, respectively) were reported for the AASs reinforced with steel fibers. The maximum strength loss was found for AASs reinforced with PVA fibers, while basalt fibers resulted lower strength loss than other nonmetallic fibers [32]. This confirms that nonmetallic fibers have different impacts on strength loss at high temperatures, depending on the properties of the matrix and bond at the fiber/matrix ITZ.

\section{Carbonation Resistance}

The chemical reaction and compounds formed during the carbonation of AASs have been formulated in the following Equations. Carbonation first causes porosity to increase due to the decalcification of $\mathrm{C}-\mathrm{S}-\mathrm{H}$ gels [59]. Calcium hydroxide behaves as a buffer and a source of calcium in OPC [60], while the formation of $\mathrm{C}-\mathrm{S}-\mathrm{H}$ phases in alkaliactivated slag-based binders consumes calcium hydroxide, consumption of large amounts of the $\mathrm{OH}^{-}$in the pore liquid, which reduces the $\mathrm{pH}$ value [61]. Second, in the presence of a small amount of solid sodium silicate, which remained unconsumed in the polymerization reactions, consumption of the $\mathrm{OH}^{-}$in the pore liquid could dissolve rapidly and release a large amount of $\mathrm{Ca}^{2+}, \mathrm{OH}^{-}, \mathrm{Na}^{+}$, and $\mathrm{SiO}_{3}{ }^{2-}$, which can react with a large amount of $\mathrm{CO}_{2}$ and consequently form $\mathrm{H}_{2} \mathrm{O}, \mathrm{CaCO}_{3}$, and $\mathrm{C}-\mathrm{S}-\mathrm{H}$ gel [62]. In this phase, porosity decreases due to the formation of crystals. In the plain AASs, the formation of the crystals introduces additional internal stresses or even local destruction in the compact matrix, which could damage the matrix due to lack of space and subsequently, a strength loss may be happened [63, 64].

$\mathrm{ca}^{2+}+\mathrm{SiO}_{3}^{2-}+n \mathrm{H}_{2} \mathrm{O} \rightarrow \mathrm{C}-\mathrm{S}-\mathrm{H}$ (High alkaline environment)

$\mathrm{Ca}^{2+}+\mathrm{SiO}_{3}^{2-}+\mathrm{Al}^{3+}+n \mathrm{H}_{2} \mathrm{O} \rightarrow \mathrm{C}-\mathrm{A}-\mathrm{S}-\mathrm{H}$

(High alkaline environment)

$\mathrm{Na}^{+}+n \mathrm{SiO}_{3}^{2-}+n \mathrm{H}_{2} \mathrm{O} \rightarrow \mathrm{Na}_{2} \mathrm{O} \cdot n \mathrm{SiO}_{2} \cdot n \mathrm{H}_{2} \mathrm{O}$ (Surplus)

$\mathrm{Na}_{2} \mathrm{O} \cdot n \mathrm{SiO}_{2} \cdot n \mathrm{H}_{2} \mathrm{O}+\mathrm{H}_{2} \mathrm{O} \rightarrow \mathrm{Na}^{+}+n \mathrm{OH}^{-}+n \mathrm{SiO}_{3}^{2-}$

Conversely, the addition of fibers increases porosity based on the fibers' content, type, length, and shape. The impacts of carbonation on the compressive strength of reinforced OAASs could be a challenge in addition to the increase in porosity due to the addition of fibers, the decrease in porosity due to the formation of crystals, and the capacity of fibers to arrest further opening of cracks. Therefore, the compressive strength of fiber reinforced compositions can be either increased or decreased when exposed to the carbonation conditions.

It is worth mentioning that carbonation conditions are also effective on this strength challenge, which these parameters are mainly included $\mathrm{CO}_{2}$ concentration, relative humidity, temperature, and exposure duration [65]. Moreover, properties of cementitious compositions (such as binder properties, alkali solution, liquid to solid ratio) could be effective [65].

Using combinations of fibers instead of single fibers can enhance mechanical properties after carbonation (see Fig. 8). Moreover, if the increased porosity at the fiber/matrix ITZ could be filled with the formed crystals, the friction between fibers and their surrounding matrix increases, which could affect the debonding of fibers and, in turn, enhance the flexural performance of the reinforced OAAS. However, it should be noted that excessive crystal formation imposes internal stress on the matrix and results in the formation of some micro-cracks, which decreases mechanical strength.

Figure 8 shows the effects of carbonation on the mechanical strength of OAASs reinforced with different fibers. As 


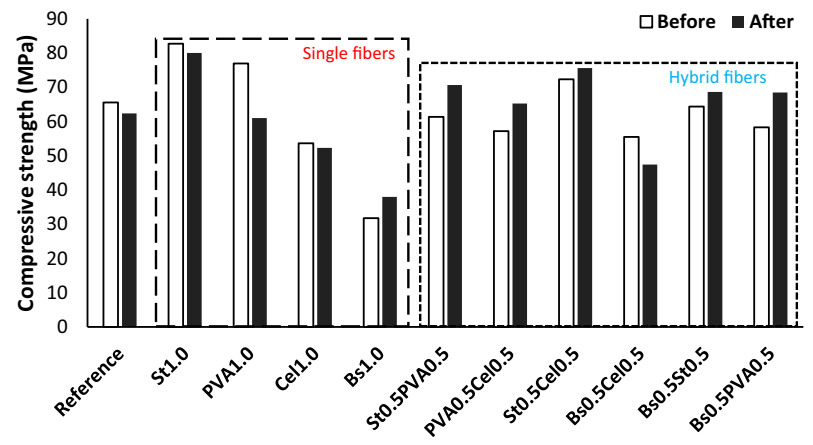

(a)

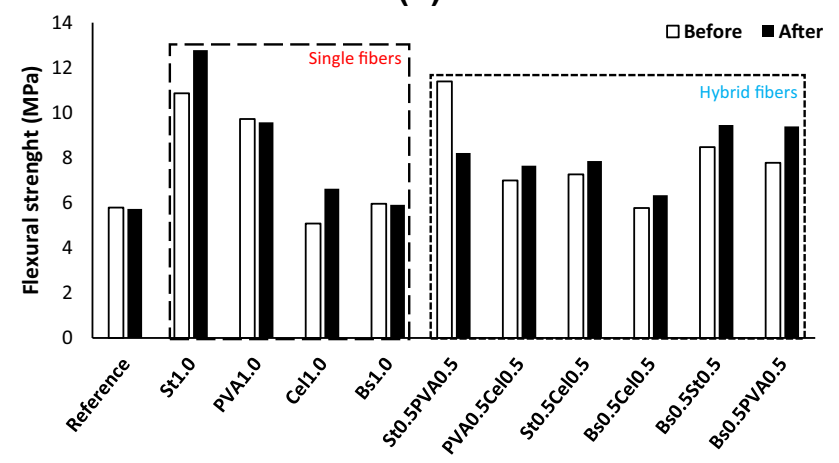

(b)

Fig. 8 Effects of carbonation on $\mathbf{a}$ compressive strength and $\mathbf{b}$ flexural strength

indicated in Fig. 8a, increases or decreases in compressive strength depend on the type and combination of fibers. Interestingly, compressive strength increased in some OAASs reinforced with hybrid fibers (St0.5PVA0.5 and PVA0.5Cel0.5), while compressive strength decreased in OAASs reinforced with single fibers after exposure to $\mathrm{CO}_{2}$ gas. The maximum increase $(20 \%)$ and decrease $(25 \%)$ in compressive strength in single-fiber reinforced OAASs were recorded for Bs1 and PVA1, respectively. Except for Bs0.5Cel0.5, the compressive strength of all hybrid-fiber reinforced OAASs increased. The maximum increase (17\%) was recorded for Bs0.5PVA0.5.

Unlike compressive strength, the flexural strength of reinforced OAASs increased or did not significantly decrease. The maximum increase in flexural strength $(30 \%)$ was reported by Cel1, followed by St1 (18\%). Except for St0.5PVA0.5, the flexural strength of all hybrid-fiber reinforced OAASs increased. The maximum increase $(20 \%)$ and decrease $(30 \%)$ in flexural strength were reported for St0.5PVA0.5 and Bs0.5PVA0.5, respectively. Mastali et al. showed that exposing AASs reinforced with PVA and polypropylene fibers to carbonation reduced compressive and flexural strength, while other fiber types (cellulose, basalt, and steel) increased these types of strength [32].

\section{Freeze/Thaw Resistance}

Freeze/thaw resistance depends on the pore structure (including, tortuosity, pore distribution, and pore size volume) of an OAAS. A higher amount of water suction results in more ice volume formation inside pores, and this expansion submits the compressive load on the matrix walls, while melting results in unloading of this imposed internal stress and decreases in pore volume. The final volume change of the pores depends on the elastic/plastic strains (i.e., permanent/recovered deformations) of the matrix, although pore sizes become larger and total porosity and tortuosity increase after performing this test. As shown in Fig. 9a, this mechanism leads to the formation of some cracks in the matrix around the single pores as well as the pore sizes become larger and total porosity increases. The increment of pore sizes may generate more single pores connected, and then tortuosity increases and it affect the water movements in the composition. Mastali et al. proposed that this type of loading/unloading due to expansion/contraction of volume could be simulated as fatigue loading [66]. Moreover, the addition of fibers can result in two different scenarios regarding freeze/thaw resistance: (1) increased porosity and changed pore structure (including, tortuosity, pore distribution, and pore size volume) and (2) fiber bridging action. Furthermore, it should be noted that the efficiency of fiber bridging action is influenced by the pore structures at the fiber/matrix ITZ. Filling pores at the ITZ with water and exposing them to freeze/thaw loading/unloading cycles degraded the bonding properties of the fiber/matrix ITZ.

Figure $9 \mathrm{~b}$ presents the compressive strength of OAASs reinforced with different fibers under cyclic freeze/thaw loadings. In this study, steel fibers were associated with highest strength loss under cyclic freeze/thaw loadings. Since the addition of steel fibers generated the maximum capillary coefficient and more water could be sucked in to the compositions, more pores were filled with water and more damage was observed (high tortuosity). Addition of different types and combinations of fibers resulted in decreases in compressive strength compared to the plain OAAS. For single-fiber reinforced OAASs, this strength loss ranged from 25\% (Cel1 and Bs1) to $55 \%$ (St1). For hybrid-fiber reinforced OAASs, the strength loss varied from $20 \%$ (St0.5PVA0.5) to $65 \%$ (Bs0.5Cel0.5).

As shown in Fig. 9c, the addition of fibers significantly affected flexural strength loss. For instance, the addition of steel fibers reduced flexural strength by around 60\% compared to specimens that were not exposed to cyclic freeze/ thaw loadings. The addition of PVA fibers had a significant effect on strength loss, limiting it to less than $1 \%$. Using cellulose and basalt fibers also limited the flexural strength loss to $20-25 \%$. In OAASs reinforced with hybrid fiber combinations, strength loss varied from $0.5 \%$ ( $\mathrm{Bs} 0.5 \mathrm{Cel} 0.5)$ to $35 \%$ 


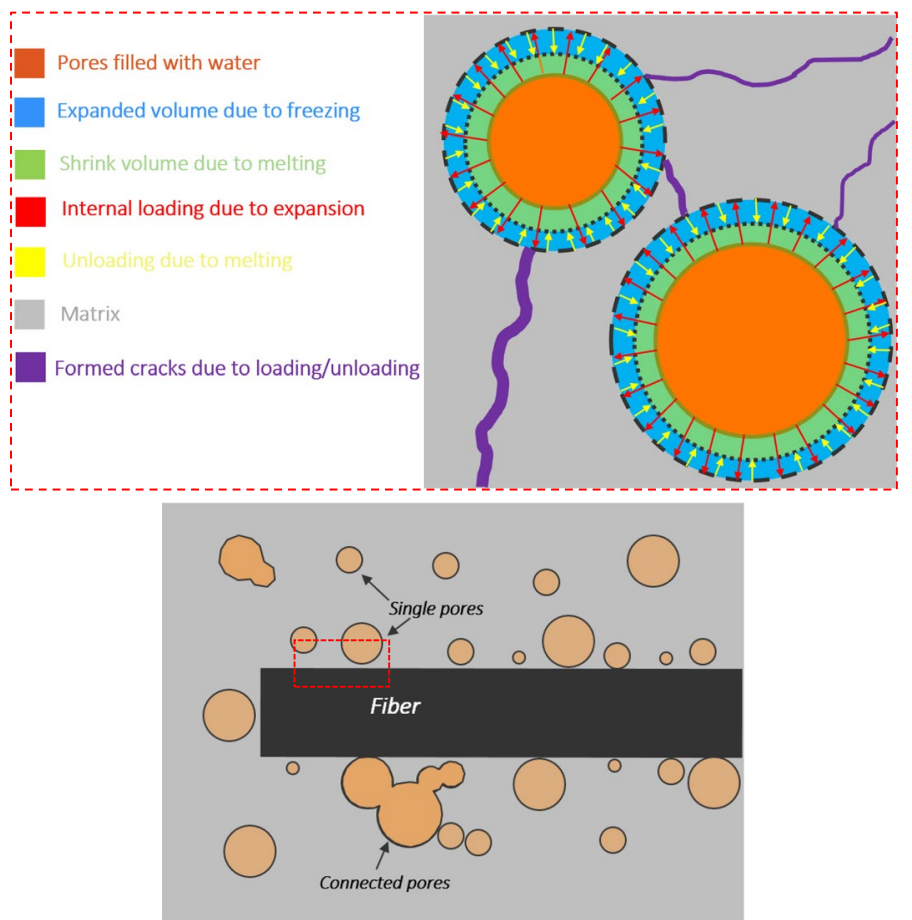

(a)

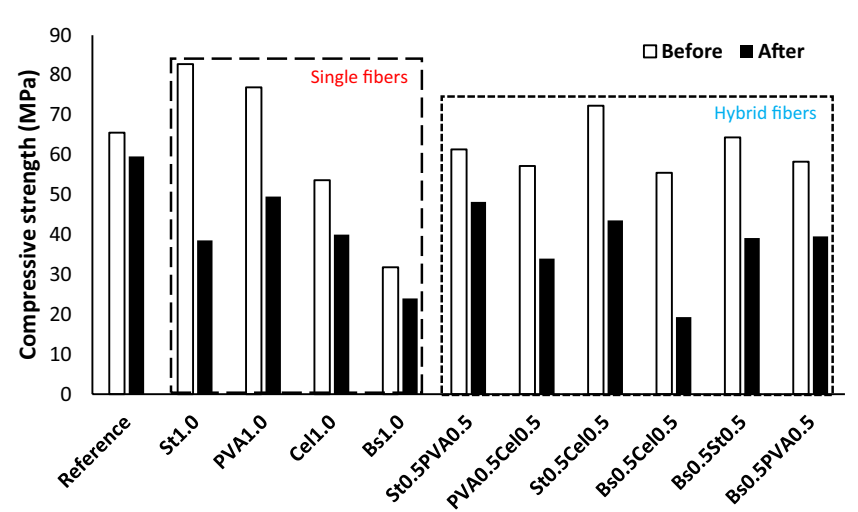

(b)

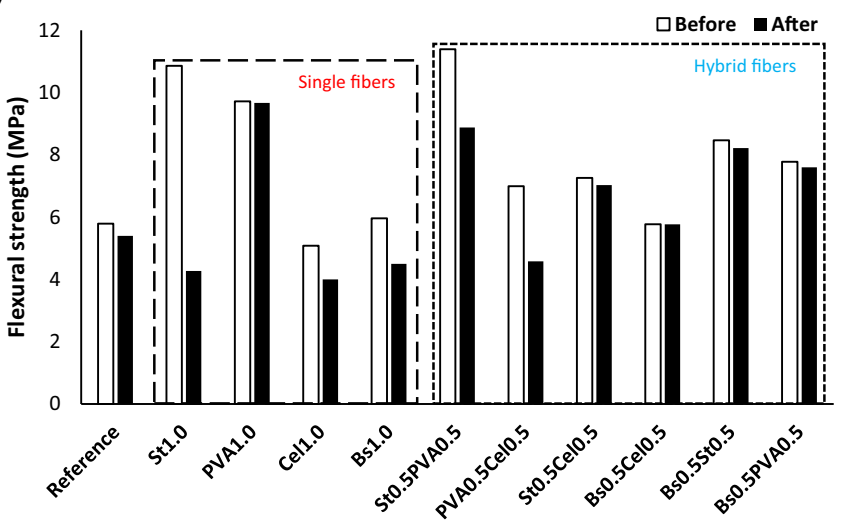

(c)

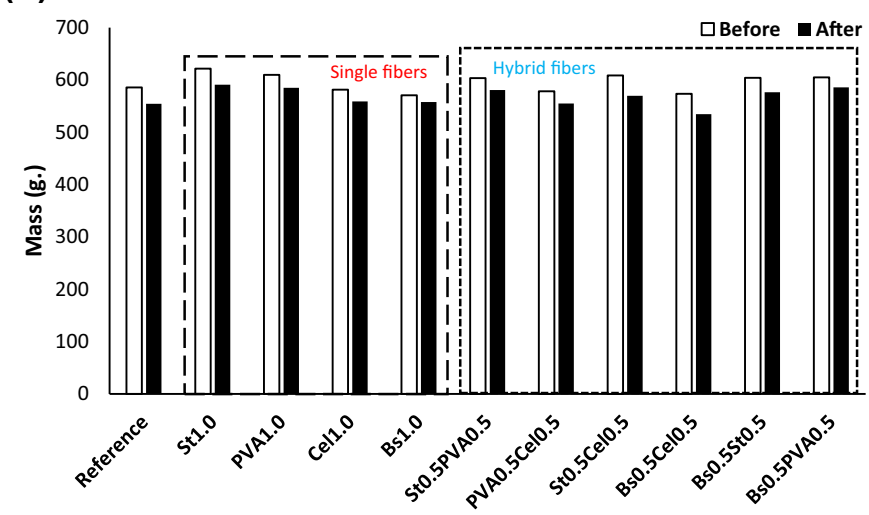

(d)

Fig. 9 a Schematic view of the impacts of cyclic freeze/thaw loadings on the performance of fiber-reinforced OAASs. b Compressive strength under cyclic freeze/thaw loadings. $\mathbf{c}$ Flexural strength under cyclic freeze/thaw loadings. $\mathbf{d}$ Mass changes under cyclic freeze/thaw loadings 
(PVA0.5Ce10.5). In general, reinforcement with a combination of fibers more effectively limited flexural strength loss than reinforcement with single fibers, although this depends on the fiber type. Moreover, it was found that adding fibers often had a greater impact on flexural strength loss than compressive strength loss.

The mass changes in OAASs reinforced with different fibers after cyclic freeze/thaw loadings are presented in Fig. 9d. Reinforcement of OAASs with single fibers limited mass loss to $2 \%$ (Bs1) to 5\% (St1). For comparison, the plain OAAS experienced mass loss of more than 5\%. Use of fiber combinations resulted in mass loss of $3 \%$ (Bs0.5PVA0.5) to $7 \%$ (Bs0.5Cel0.5). Therefore, it can be concluded that addition of single fibers (regardless of their type) could reduce mass loss.

Mastali et al. examined the freeze/thaw resistance of AASs reinforced with different fibers after exposure to 60 freeze/thaw cycles [32]. They reported mass loss of $1 \%(1 \%$ PVA) to $3 \%$ (1.5\% basalt). The maximum compressive and flexural strength losses were $25 \%$ and $55 \%$, respectively, but reinforcing AASs with different fibers had a greater impact on compressive strength loss than flexural strength loss [32]. Since the fiber type and test conditions in [32] and the present paper were exactly the same, it be concluded that differences in the nature of OAASs and AASs affect the performance of fibers regarding strength loss.

\section{Conclusions}

This paper presents the experimental results regarding the durability of OAASs reinforced with different fiber types and combinations. The following conclusions can be made based on the results:

1. As expected, compressive strength can either increase or decrease with the addition of fibers, and flexural strength typically increases. In general, hybrid fibers have a greater positive impact on flexural strength compared to compressive strength.

2. All the plain and reinforced OAASs have high acid resistance. The mass loss in all reinforced compositions was limited to $2 \%$ after exposure to sulfuric acid for 9 days.

3. Steel fibers can resist the strength loss generated by high temperatures in both single and hybrid systems. Under high temperature conditions, the maximum residual strength was around 40\% (33 MPa) of the un-heated strength for St1. This is an acceptable strength for fire resistance in real structural applications.

4. In general, the addition of single fibers decreases carbonation resistance in relation to compressive strength, while the use of hybrid fibers increases it. Moreover, carbonation resistance in relation to flexural strength typically increases when OAASs are reinforced, regardless of the fiber type or combination with which they are reinforced.

5. Except for steel fiber (St1), all single and hybrid fibers increased the OAASs' total porosity and water absorption by immersion. The addition of steel as a single fiber had no impact on total porosity. Since steel fibers have the maximum positive impact on tortuosity and water suction, the steel fibers used in this study were associated with highest strength loss under freeze/thaw cyclic loadings.

Acknowledgements Open access funding provided by University of Oulu including Oulu University Hospital. This work received funding from SYMMET (Grant ID: 4236/31/2018), ERAMIN2/Business (Grant ID: 24302797), and GEOBIZ project (Grant ID: 1105/31/2016).

\section{Compliance with Ethical Standards}

Conflict of interest The authors declare that they have no conflict of interest.

Open Access This article is licensed under a Creative Commons Attribution 4.0 International License, which permits use, sharing, adaptation, distribution and reproduction in any medium or format, as long as you give appropriate credit to the original author(s) and the source, provide a link to the Creative Commons licence, and indicate if changes were made. The images or other third party material in this article are included in the article's Creative Commons licence, unless indicated otherwise in a credit line to the material. If material is not included in the article's Creative Commons licence and your intended use is not permitted by statutory regulation or exceeds the permitted use, you will need to obtain permission directly from the copyright holder. To view a copy of this licence, visit http://creativecommons.org/licenses/by/4.0/.

\section{References}

1. Zurer, P.S.: Economic considerations enter fray over global climate change policies. Chem. Eng. News 69, 7-13 (1991)

2. Mastali, M., Kinnunen, P., Dalvand, A., Mohammadi, F.R., Illikainen, M.: Drying shrinkage in alkali-activated binders-a critical review. Constr. Build. Mater. 190, 533-550 (2018)

3. Provis, J.: Alkali-activated materials. Cem. Concr. Res. 114, 40-48 (2018)

4. Luukkonen, T., Abdollahnejad, Z., Yliniemi, J., Kinnunen, P., Illikainen, M.: One-part alkali-activated materials: a review. Cem. Concr. Res. 103, 21-34 (2018)

5. Pacheco-Torgal, F., Castro-Gomes, J., Jalali, S.: Alkali-activated binders: a review part 1 . Historical background, terminology, reaction mechanisms and hydration products. Constr. Build. Mater. 22, 1305-1314 (2008)

6. Pacheco-Torgal, F., Castro-Gomes, J., Jalali, S.: Alkali-activated binders: a review. Part 2. About materials and binders manufacture. Constr. Build. Mater. 22, 1315-1322 (2008)

7. Abdollahnejad, Z., Pacheco-Torgal, F., Barroso, A.J.: Development of Foam one-part geopolymers with enhanced thermal 
insulation performance and low carbon dioxide emissions. Adv. Mater. Res. 1129, 565-572 (2015)

8. Duxson, P., Provis, J.L.: Designing precursors for geopolymer cements. J. Am. Ceram. Soc. 91, 3864-3869 (2008)

9. Ye, N., Chen, Y., Yang, J., Liang, S., Hu, Y., Xiao, B., Huang, Q., Shi, Y., Hu, J., Wu, X.: Co-disposal of MSWI fly ash and Bayer red mud using an one-part geopolymeric system. J. Hazard. Mater. 318, 70-78 (2016)

10. Yang, K.H., Song, J.K., Lee, J.S.: Properties of alkali-activated mortar and concrete using lightweight aggregates. Mater. Struct. 43, 403-416 (2010)

11. Hajimohammadi, A., Ngo, T., Mendis, P., Kashani, A., van Deventer, J.S.J.: Alkali activated slag foams: the effect of the alkali reaction on foam characteristics. J. Clean. Prod. 147, 330-339 (2017)

12. Collins, F., Sanjayan, J.G.: Microcracking and strength development of alkali activated slag concrete. Cem. Concr. Compos. 23, 345-352 (2001)

13. Arbi, K., Nedeljković, M., Zuo, Y., Ye, G.: A review on the durability of alkali-activated fly Ash/slag systems: advances, issues, and perspectives. Ind. Eng. Chem. Res. 55, 5439-5453 (2016)

14. van Deventer, J.S.J., Feng, D., Duxson, P.: Dry mix cement composition, methods and system involving same, US Patent 7691198 B2 (2010)

15. Li, X., Wang, Z., Jiao, Z.: Influence of curing on the strength development of calcium-containing geopolymer mortar. Materials 6, 5069-5076 (2013)

16. Abdollahnejad, Z., Mastali, M., Luukkonen, T., Kinnunen, P., Illikainen, M.: Fiber-reinforced one-part alkali-activated slag/ ceramic binders. Ceram. Int. 44, 8963-8976 (2018)

17. Luukkonen, T., Abdollahnejad, Z., Yliniemi, J., Kinnunen, P., Illikainen, M.: Comparison of alkali and silica sources in onepart alkali-activated blast furnace slag mortar. J. Clean. Prod. 187, 171-179 (2018)

18. Abdollahnejad, Z., Luukkonen, T., Mastali, M., Kinnunen, P., Illikainen, M.: Development of one-part alkali activated ceramic/ slag binders containing recycled ceramic aggregates. J. Mater. Civil Eng. 31(2), 04018386 (2018). https://doi.org/10.1061/ (ASCE)MT.1943-5533.0002608

19. Abdollahnejad, Z., Luukkonen, T., Mastali, M., Giosue, C., Favoni, O., Ruello, M.L., Kinnunen, P., Illikainen, M.: The microstructural analysis and strength development of one-part alkali slag/ceramic activated binders under different curing regimes. Waste Biomass Valorization (2019). https://doi.org/10.1007/s1264 9-019-00626-9

20. Choi, S., Choi, J., Song, J., Lee, B.: Rheological and mechanical properties of fiber-reinforced alkali-activated composite. Constr. Build. Mater. 96, 112-118 (2015)

21. Bhutta, A., Borges, P.H.R., Zanotti, Z., Farooq, M., Banthia, N.: Flexural behavior of geopolymer composites reinforced with steel and polypropylene macro fibers. Cem. Concr. Compos. 80, 31-40 (2017)

22. Puertas, F., Amat, T., Fernández-Jiménez, A., Vázquez, T.: Mechanical and durable behaviour of alkaline cement mortars reinforced with polypropylene fibres. Cem. Concr. Res. 33, 2031$2036(2003)$

23. Kim, S.-W., Jang, S.-J., Kang, D.-H., Ahn, K.-L., Yun, H.-D.: Mechanical properties and eco-efficiency of steel fiber reinforced alkali-activated slag concrete. Materials 8(11), 7309-7321 (2015)

24. Bernal, S., Gutierrez, R., Delvasto, S., Rodriguez, E.: Performance of an alkali-activated slag concrete reinforced with steel fibers. Constr. Build. Mater. 24, 208-214 (2010)

25. Carabba, L., Santandrea, M., Carloni, C., Manzi, S., Bignozzi, M.: Steel fiber reinforced geopolymer matrix (S-FRGM) composites applied to reinforced concrete structures for strengthening applications: a preliminary study. Composite Part B 128, 83-90 (2017)
26. Vilaplana, J.L., Baeza, F.J., Galao, O., Alcocel, E.G., Zornoza, E., Garcés, P.: Mechanical properties of alkali activated blast furnace slag pastes reinforced with carbon fibers. Constr. Build. Mater. 116, 63-71 (2016)

27. Bernal, S., Bejarano, J., Garzón, C., Mejía de Gutiérrez, R., Delvasto, S., Rodríguez, E.: Performance of refractory aluminosilicate particle/fiber-reinforced geopolymer composites. Composite Part B 43, 1919-1928 (2012)

28. Ohno, M., Li, V.C.: A feasibility study of strain hardening fiber reinforced fly ash-based geopolymer composites. Constr. Build. Mater. 57, 163-168 (2014)

29. Choi, J., Lee, B., Ranade, R., Li, V.C., Lee, Y.: Ultra-high-ductile behavior of a polyethylene fiber-reinforced alkali-activated slagbased composite. Cement. Concr. Compos. 70, 153-158 (2016)

30. Lee, Y., Choi, J., Kim, H., Lee, B.: Effects of a defoamer on the compressive strength and tensile behavior of alkali-activated slagbased cementless composite reinforced by polyethylene fiber. Compos. Struct. 172, 166-172 (2017)

31. Aydın, S., Baradan, B.: The effect of fiber properties on high performance alkali-activated slag/silica fume mortars. Composite Part B 45, 63-69 (2013)

32. Mastali, M., Alzaza, A., Mohammad Shaad, K., Kinnunen, P., Abdollahnejad, Z., Illikainen, M.: Using carbonated BOF slag aggregates in alkali-activated concretes. Materials 12(8), 1288 (2019). https://doi.org/10.3390/ma12081288

33. Puertas, F., Gil-Maroto, A., Palacios, M., Amat, T.: Alkali-activated slag mortars reiforced with ar glassfibre. Performance and properties. Mater. Constr. 56, 79-90 (2006)

34. Nematollahi, B., Sanjayan, J., Qiu, J., Yang, E.: Micromechanicsbased investigation of a sustainable ambient temperature cured one-part strain hardening geopolymer composite. Constr. Build. Mater. 131, 552-563 (2017)

35. Nematollahi, B., Sanjayan, J., Qiu, J., Yang, E.: High ductile behavior of a polyethylene fiber-reinforced one-part geopolymer composite: a micromechanics-based investigation. Arch. Civil Mech. Eng. 17, 555-563 (2017)

36. Nematollahi, B., Sanjayan, J.: Tensile strain hardening behavior of PVA fiber-reinforced engineered geopolymer composite. J. Mater. Civil Eng. 27, 04015001 (2015)

37. NORMENSAND Characteristics. https://www.normensand.de/en/ products/cen-standard-sand-en-196-1/. Accessed 06 June 2019.

38. Jang, J., Lee, N., Lee, H.: Fresh and hardened properties of alkaliactivated fly ash/slag pastes with superplasticizers. Constr. Build. Mater. 50, 169-176 (2014)

39. Nematollahi, B., Sanjayan, J.: Effect of different superplasticizers and activator combinations on workability and strength of fly ash based geopolymer. Mater. Des. 57, 667-672 (2014)

40. ASTM C109/C109M-16a. Standard Test Method for Compressive Strength of Hydraulic Cement Mortars (Using 2-in. or [50-mm] Cube Specimens). ASTM International, West Conshohocken, PA http://www.astm.org/ (2016)

41. ASTM C78/C78M-18. Standard Test Method for Flexural Strength of Concrete (Using Simple Beam with Third-Point Loading). ASTM International, West Conshohocken, PA http://www.astm. org/ (2018)

42. BS EN 1015-18:2002. Methods of test for mortar for masonry. Determination of water absorption coefficient due to capillary action of hardened mortar, British Standards Institution.

43. BS EN 1015-18:2002. Methods of test for mortar for masonry. Determination of water absorption coefficient due to capillary action of hardened mortar, UK.

44. Pacheco-Torgal, F., Abdollahnejad, Z., Aires Camoes, M., Jamshidi, Y.D.: Durability of alkali activated binders: a clear advantage over Portland cement or an unproven issue? Constr. Build. Mater. 30, 400-405 (2012) 
45. Chan, Y.N., Peng, G.F., Anson, M.: Residual strength and pore structure of high-strength concrete and normal strength concrete after exposure to high temperatures. Cement. Concr. Compos. 21, 23-27 (1999)

46. PD CEN/TS 12390-9:2016. Testing hardened concrete. Freezethaw resistance with de-icing salts. Scaling, UK

47. Abdollahnejad, Z., Mastali, M., Mastali, M., Dalvand, A.: A comparative study on the effects of recycled glass fiber on drying shrinkage rate and mechanical properties of the self-compacting concrete and fly ash/slag geopolymer concrete. J. Mater. Civil Eng. 29(8), 04017076 (2017). https://doi.org/10.1061/(ASCE) MT.1943-5533.0001918

48. Kheradmand, M., Mastali, M., Abdollahnejad, Z., Pacheco-Torgal, F.: Experimental and numerical investigations on the flexural performance of geopolymers reinforced with short hybrid polymeric fibres. Composites B 126, 108-118 (2017)

49. Mastali, M., Dalvand, A., Sattarifard, A.R., Abdollahnejad, Z., Illikainen, M.: Characterization and optimization of hardened properties of self-consolidating concrete incorporating recycled steel, industrial steel, polypropylene and hybrid fibres. Composite Part B 151, 186-200 (2018)

50. Mastali, M., Dalvand, A., Sattarifard, A.R., Illikainen, M.: Development of eco-efficient and cost-effective self-consolidation concretes reinforced with hybrid industrial/recycled steel fibers. Constr. Build. Mater. 166, 214-226 (2018)

51. Mastali, M., Abdollahnejad, Z., Pacheco-Torgal, F.: Performance of waste based alkaline mortars submitted to accelerated carbon dioxide curing. Resour. Conserv. Recycl. 129, 12-19 (2018)

52. Abdollahnejad, Z., Pacheco-Torgal, F., Aguiar, J.B.: Cost-efficient one-part alkali-activated mortars with low global warming potential for floor heating systems applications. J. Eur. J. Environ. Civil Eng. (2016). https://doi.org/10.1080/19648189.2015.1125392

53. Zhang, W., Yao, X., Yang, T., Zhang, Z.: The degradation mechanisms of alkali-activated fly ash/slag blend cements exposed to sulphuric acid. Constr. Build. Mater. 186, 1177-1187 (2018)

54. Allahverdi, A., Skvara, F.: Sulfuric acid attack on hardened paste of geopolymer cements-Part 2. Corrosion mechanism at mild and relatively low concentrations. Ceram. Silik. 50, 1-4 (2006)

55. Allahverdi, A., Skvara, F.: Sulfuric acid attack on hardened paste of geopolymer cements Part 1. Mechanism of corrosion at relatively high concentrations. Ceram. Silik. 49, 225-229 (2005)

56. Bernal, S.A., Rodríguez, E.D., Mejía de Gutiérrez, R., Provis, J.L.: Performance of alkali-activated slag mortars exposed to acids. J. Sustain. Cem.-Based Mater. 1, 138-151 (2012)
57. Funke, H., Gelbrich, S., Kroll, L.: The durability and performance of short fibers for a newly developed alkali-activated binder. Fibers 4(1), 11 (2016). https://doi.org/10.3390/fib4010011

58. Lourenço, L., Barros, J., Alves, J.A.: Fiber reinforced concrete of enhanced fire resistance for tunnel segments. ACI Mater. J. 276, $1-34(2011)$

59. Thomas, J.J., Chen, J.J., Allen, A.J., Jennings, H.M.: Effects of decalcification on the microstructure and surface area of cement and tricalcium silicate pastes. Cem. Concr. Res. 34, 2297-2307 (2004)

60. Bakharev, T., Sanjayan, J., Cheng, Y.B.: Resistance of alkaliactivated slag concrete to carbonation. Cem. Concr. Res. 31, 1277-1283 (2001)

61. Sharma, R.L., Pandey, S.P.: Influence of mineral additives on the hydration characteristics of ordinary Portland cement. Cem. Concr. Res. 29, 1525-1529 (1999)

62. Mastali, M., Shaad, M.K., Abdollahnejad, Z., Falah, M., Kinnunen, P., Illikainen, M.: Towards sustainable bricks made with fiber-reinforced alkali-activated desulfurization slag mortars incorporating carbonated basic oxygen furnace aggregates. Constr. Build. Mater. 232, 117258 (2019)

63. Abdollahnejad, Z., Dalvand, A., Mastali, M., Luukkonen, T., Illikainen, M.: Effects of waste glass and calcium hydroxide on crystallinity and strength of alkali-activated fly ash mortars. Mag. Concr. Res. (2018). https://doi.org/10.1680/jmacr.18.00300

64. Ma, X., Zhang, Z., Wang, A.: The transition of fly ash-based geopolymer gels into ordered structures and the effect on the compressive strength. Constr. Build. Mater. 104, 25-33 (2016)

65. Bernal, S.A., Provis, J.L.: Durability of alkali-activated materials: progress and perspectives. J. Am. Ceram. Soc. 97, 997-1008 (2014)

66. Mastali, M., Kinnunen, P., Karhu, M., Abdollahnejad, Z., Korat, L., Ducman, V., Alzaza, A., Illikainen, M.: Impacts of casting scales and harsh conditions on the thermal, acoustic, mechanical properties of indoor acoustic panels made with fiber-reinforced alkali-activated slag foam concretes. Materials 12(5), 825 (2019). https://doi.org/10.3390/ma12050825

Publisher's Note Springer Nature remains neutral with regard to jurisdictional claims in published maps and institutional affiliations.

\section{Affiliations}

\section{Z. Abdollahnejad $^{1,2} \cdot$ M. Mastali $^{1} \cdot$ M. Falah $^{1} \cdot \mathrm{K}$ Mohammad Shaad $^{1} \cdot$ T. Luukkonen $^{1} \cdot$ M. Illikainen $^{1}$}

1 Fiber and Particle Engineering, Faculty of Technology, University of Oulu, P.O. Box 4300, 90014 Oulu, Finland
2 Civil \& Environmental Engineering Department, University of Connecticut, 261 Glenbrook Road Unit 3037, Storrs, CT 06269-3037, USA 